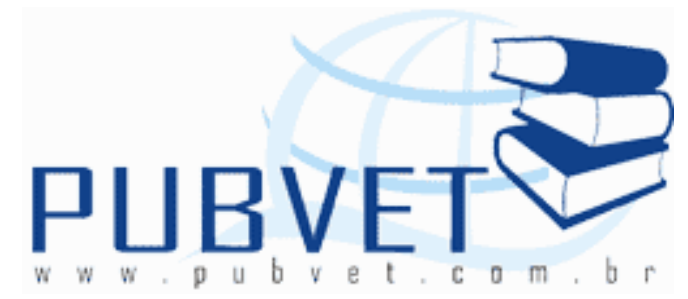

PUBVET, Publicações em Medicina Veterinária e Zootecnia.

\title{
Lombalgia equina: diagnóstico e tratamento
}
Adriana Borges Mendes ${ }^{1}$, Giuliano Moraes Figueiró ${ }^{2}$, Flavia de Almeida Lucas ${ }^{3}$, Graziela Barioni $^{4}$

Trabalho de Conclusão de Curso - Curso de Medicina Veterinária, Centro Universitário Vila Velha, Vila Velha - ES, 2010.

${ }^{1}$ Médica Veterinária autônoma - Vila Velha - ES

${ }^{2}$ Professor Doutor do Centro Universitário do Espírito Santo (UNESC) e Escola Superior São Francisco de Assis (ESFA)

3 Professora Doutora da Universidade Estadual Paulista "Júlio de Mesquita Filho" - Unesp campus Araçatuba

${ }^{4}$ Professora Doutora do Centro de Ciências Agrárias da Universidade Federal do Espírito Santo - CCA- UFES. graziela.barioni@terra.com.br

\section{Resumo}

A lombalgia é considerada uma causa importante de claudicação e queda de performance, porém identificar a localização das lesões e quantificar a intensidade da dor é difícil, pois frequentemente o sinal clínico mais evidente, em alguns casos, não é a dor propriamente dita e sim, o baixo desempenho atlético. O diagnóstico e tratamento desta enfermidade estão associados a um alto custo e possuem um forte impacto na indústria equina, uma vez que resulta em perdas econômicas diretas. O diagnóstico das lombalgias se faz por meio do exame físico e dos exames complementares, que incluem radiografia, 
MENDES, A.B. et al. Lombalgia equina: diagnóstico e tratamento. PUBVET, Londrina, V. 7, N. 17, Ed. 240, Art. 1583, Setembro, 2013.

ultra-sonografia, termografia e bloqueios anestésicos. As principais lesões causadoras de lombalgias nos equinos são o contato ou sobreposição dos processos espinhosos, a desmite supraespinhosa, a osteoartrite dos processos articulares, as lesões de corpo vertebral e a miosite. As medidas terapêuticas utilizadas no tratamento destas enfermidades são antiinflamatórios esteróides sistêmicos, infiltrações locais, acupuntura, quiropraxia, fisioterapia, modificações no treinamento e cirurgias.

Palavras-chave: equinos, lombalgia, claudicação, "kissing spines", desmite, osteoartrite, espondilose vertebral.

\title{
Equine back pain: diagnosis and treatment
}

\begin{abstract}
Low back pain is considered a major cause of lameness and performance decay, but identify the location of the lesions and quantify the intensity of pain is difficult because often the most obvious clinical sign, in some cases, is not the pain itself, but, low athletic performance. The diagnosis and treatment of this disease are associated with a high cost and have a strong impact on the equine industry, since it results in direct economic losses. The diagnosis of low back pain is made through physical examination and additional tests, including radiography, ultrasound, thermography and blockades. Major injuries causing back pain in horses is the contact or overlap of the spinous processes, supraspinous desmitis, osteoarthritis of the articular processes, vertebral body lesions and myositis. Therapeutic measures used in the treatment of these diseases are systemic inflammatory steroid, local infiltration, acupul re, chiropractic, physical therapy, changes in training and surgeries.
\end{abstract}

Keywords: horses, back pain, lameness, "kissing spines", desmitis, osteoarthritis, spinal spondylosis. 
MENDES, A.B. et al. Lombalgia equina: diagnóstico e tratamento. PUBVET, Londrina, V. 7, N. 17, Ed. 240, Art. 1583, Setembro, 2013.

\section{Introdução}

No Brasil, o agronegócio do cavalo é responsável por movimentar 7,5 bilhões de reais ao ano, de modo que a parcela movimentada pelo departamento esportivo corresponde a cerca de 900 milhões de reais, segundo um trabalho elaborado, há pouco mais de dois anos, pela Esalq/USP (NASCIMENTO, 2009).

A lombalgia é resultado de uma desordem estrutural ou funcional na coluna vertebral dos equinos. A dor lombar é uma causa importante para a queda de desempenho atlético, sendo considerada uma das principais causas de claudicação em equinos (MARTIN JÚNIOR e KLIDE, 1999; TURNER, 2003; DESBROSSE e VANDEWEERD, 2006).

De acordo com Alves et al. (2007), as lombalgias correspondem a 4,35\% da casuística de enfermidades locomotoras. Entretanto, um estudo realizado por Landman et al. (2004) afirmou que a lombalgia foi diagnosticada em $32 \%$ dos animais que apresentavam claudicação. Apesar da grande incidência, problemas relacionados à coluna vertebral em equinos são pouco diagnosticados devido a falta de conhecimento anatômico da coluna vertebral, a carência de informações com relação a etiopatogenia das lesões toracolombares e, a dificuldade de acesso às estruturas afetadas através da palpação e de imagens diagnósticas (FONSECA, 2005; ALVES et al., 2007).

O diagnóstico e tratamento da dor lombar estão associados a alto custo e forte impacto na indústria equina, devido à queda no desempenho atlético. Sendo assim, as enfermidades toracolombares representam um desafio ao Medico Veterinário, que visa promover não apenas o alívio da dor, mas, principalmente, reinstituir o uso atlético do cavalo e diminuir as perdas econômicas. Assim, se observa um crescente interesse em pesquisas direcionadas a uma melhor qualidade do diagnóstico e do tratamento, principalmente de terapias alternativas que resultem em maior velocidade no 
MENDES, A.B. et al. Lombalgia equina: diagnóstico e tratamento. PUBVET, Londrina, V. 7, N. 17, Ed. 240, Art. 1583, Setembro, 2013.

processo de recuperação e, consequentemente, em uma redução no período de afastamento das atividades esportivas (FONSECA, 2008).

O objetivo dessa revisão de literatura foi descrever a anatomia da coluna toracolombar dos equinos e ressaltar o diagnóstico e o tratamento das principais lesões toracolombares causadoras da lombalgia equina.

\section{Revisão de literatura}

\subsection{Anatomia e biomecânica da coluna toracolombar equina}

A coluna vertebral é composta pelas vértebras, que são ossos separados, unidos de forma estável por ligamentos e músculos, que proporcionam estabilidade e movimento a coluna vertebral (HAUSSLER, 1999a; DYCE, SACK e WENSING, 2004). No equino, a coluna toracolombar é constituída por dezoito vértebras torácicas ( $\mathrm{T} 1$ a T18), seis vértebras lombares ( $\mathrm{L} 1$ a L6) e cinco vértebras sacrais fundidas (S1 a S5) (GETTY, 1986; HAUSSLER, 1999a; DENOIX e DYSON, 2003; DYCE, SACK e WENSING, 2004). Variações congênitas nas articulações da coluna vertebral podem ser encontradas em alguns cavalos. A mais comum é a fusão da última vértebra lombar com a primeira sacral, denominada sacralização da sexta vértebra lombar (Figura1). A anquilose intervertebral modifica a biomecânica da região das vértebras envolvidas, especialmente na junção lombossacra, já que esta é a articulação com maior mobilidade entre as vértebras T2 e S1 (GETTY, 1986; HAUSSLER, 1999a; DENOIX e DYSON, 2003; DYCE, SACK e WENSING, 2004; DENOIX, AUDIGIÉ e COUDRY, 2005). 


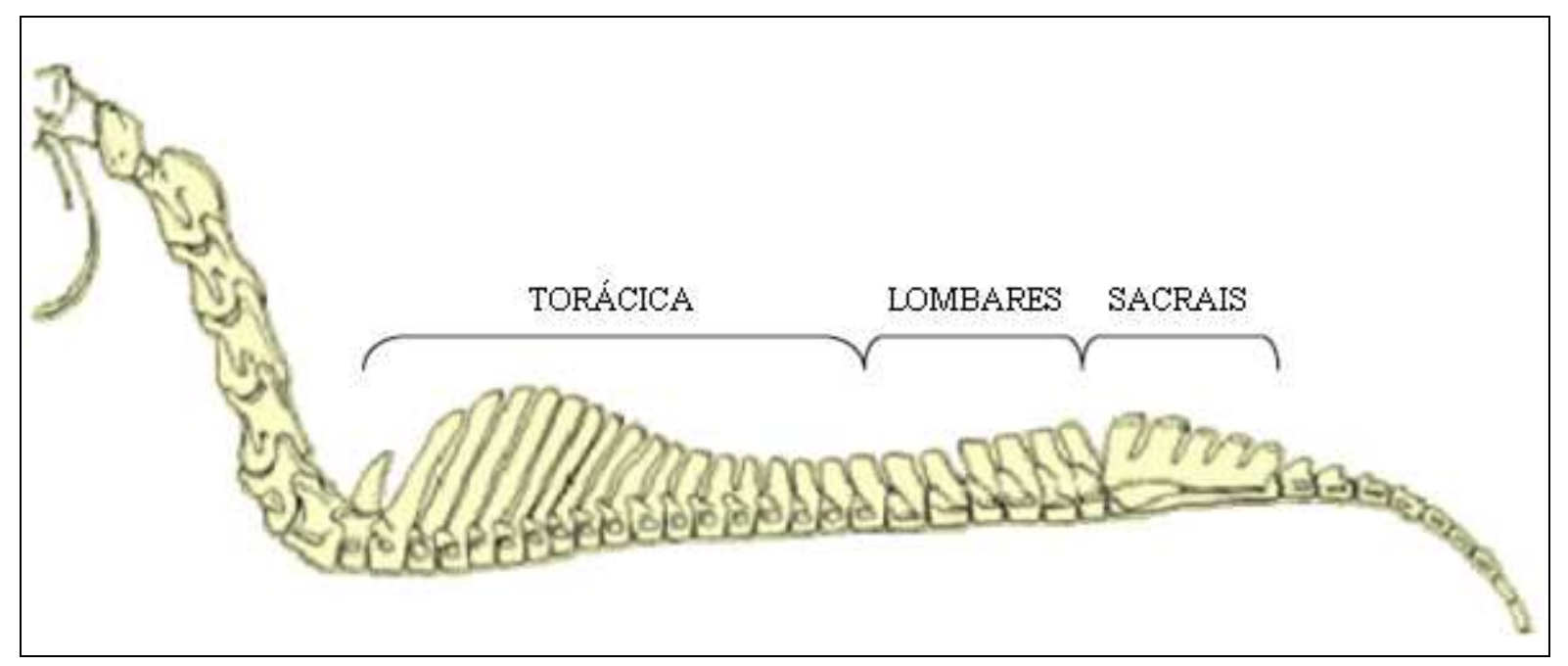

Figura 1. Estrutura óssea da coluna vertebral dos equinos, mostrando as vértebras torácicas (T1 a T18), lombares (L1 a L6) e sacrais (S1 a S5) (FONSECA, 2008).

Uma vértebra típica é composta por corpo, arco e processos, que variam em forma e tamanho em cada região (Figura 2). As primeiras dez vértebras torácicas possuem longos processos espinhosos, com orientação dorsocaudal (Figura 1), onde se insere o ligamento supraespinhoso. A vértebra anticlinal, vértebra que possui o processo espinhoso perpendicular ao eixo vertebral, geralmente é a T15. Caudal a essa vértebra, os processos espinhosos passam a possuir orientação dorsocranial (Figura 1 ) até atingir o sacro. Os processos espinhosos de L6 e S1 são divergentes, na maioria dos cavalos, o que possibilita um amplo movimento ventrodorsal da articulação lombossacra (GETTY, 1986; SISSON, 1986b; DENOIX, 1999a; HAUSSLER, 1999a; DENOIX e DYSON, 2003). 


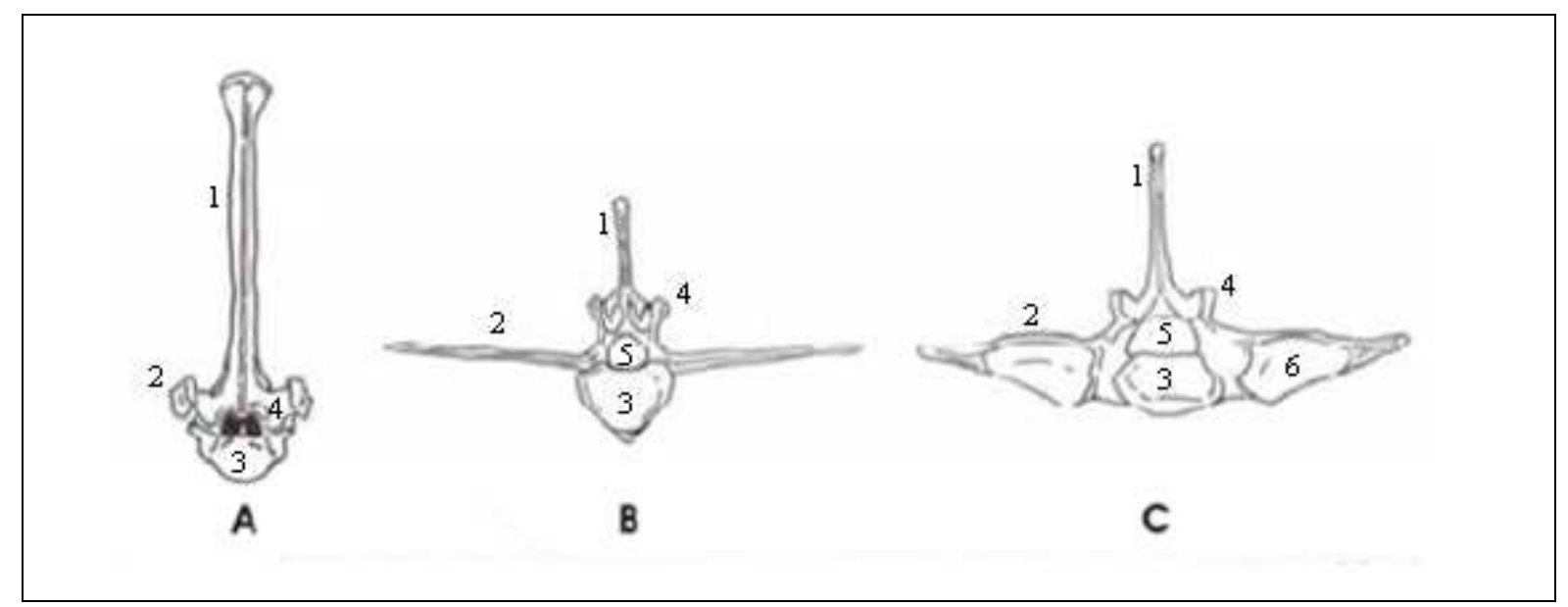

Figura 2. Principais estruturas componentes das vértebras dos equinos. 1 Processo espinhoso; 2 - Processo transverso; 3 - Corpo vertebral; 4 Processo articular; 5 - Canal vertebral; 6 - Articulação intertransversa. A - Vértebra torácica (T8); B - Vértebra lombar (L1); C - Vértebra lombar (L6) (FONSECA, 2008).

Os processos transversos das vértebras lombares a partir de L5, e algumas vezes de L4, se articulam por meio de articulações sinoviais, denominadas articulações intertransversas, que limitam a movimentação lateral desta região (GETTY, 1986; SISSON, 1986b; HAUSSLER, 1999a; DENOIX e DYSON, 2003). A estabilidade das vértebras da coluna toracolombar é promovida pelos ligamentos supra e interespinhoso, pelas articulações dos processos articulares, pelas articulações entre os corpos vertebrais e pelos ligamentos longitudinal ventral e dorsal (DENOIX, 1987; TOWNSEND, LEACH e FRETZ, 1983; DENOIX, 1999a; HAUSSLER, 1999a; DENOIX e DYSON, 2003).

Os ligamentos supra e interespinhoso (Figura 3), que promovem a estabilidade dos processos espinhosos, são mais espessos e elásticos na região torácica cranial e média, permitindo maior movimento a esta região, quando comparada à região torácica caudal e lombar (SISSON, 1986b; DENOIX, 1987; 
MENDES, A.B. et al. Lombalgia equina: diagnóstico e tratamento. PUBVET, Londrina, V. 7, N. 17, Ed. 240, Art. 1583, Setembro, 2013.

TOWNSEND, LEACH e FRETZ, 1983; DENOIX, 1999a; HAUSSLER, 1999a; DENOIX e DYSON, 2003).

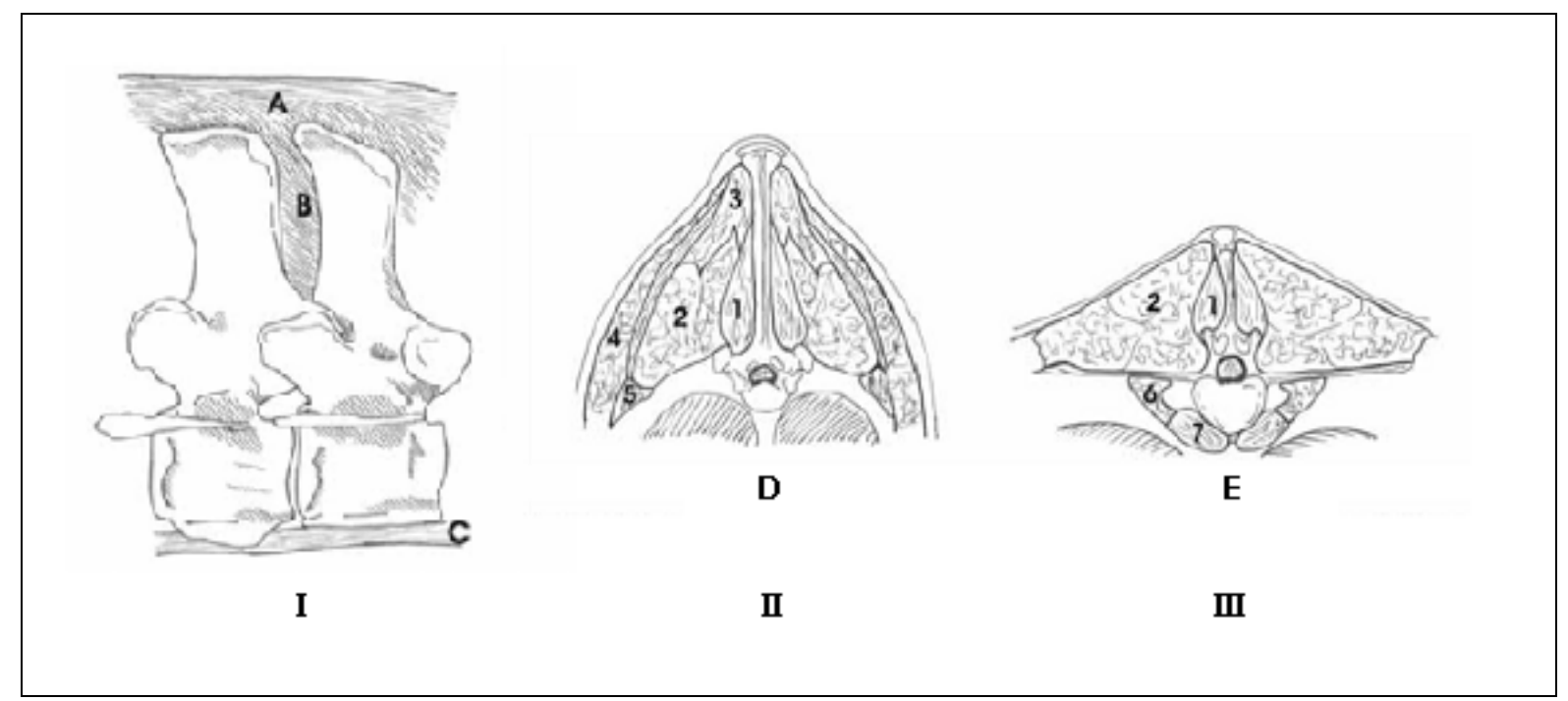

Figura 3. I - Vista lateral das vértebras L4 e L5 mostrando os principais ligamentos da coluna vertebral dos equinos. A - Ligamento supraespinhoso; B - Ligamento interespinhoso; C - Ligamento longitudinal ventral. II e III - Vista lateral do corte transversal dos músculos da região toracolombar dos equinos. D - Região torácica; E Região lombar. 1 - Músculo multífidus; 2 - Músculo longo dorsal; 3 Músculo espinhal; 4 - Músculo grande dorsal; 5- Músculo iliocostal; 6Músculo psoas maior; 7- Músculo psoas menor (FONSECA, 2008).

Os processos articulares craniais e caudais se articulam através de articulações sinoviais intervertebrais, que se encontram na base dos processos espinhosos, localizadas simetricamente de cada lado do plano mediano (SISSON, 1986a; HAUSSLER, 1999a; DENOIX e DYSON, 2003). Estas são articulações sinoviais típicas, com cartilagem articular e uma cavidade fechada que contém líquido sinovial, membrana sinovial e cápsula articular fibrosa (DENOIX e DYSON, 2003). Os processos articulares até a vértebra T12 possuem uma única e plana face articular, as vértebras entre T12 e T16 possuem duas faces articulares 
MENDES, A.B. et al. Lombalgia equina: diagnóstico e tratamento. PUBVET, Londrina, V. 7, N. 17, Ed. 240, Art. 1583, Setembro, 2013.

anguladas, e de T17 até S1 as faces articulares são congruentes com formato cilíndrico alinhadas ao eixo paramediano. Essas variações regionais estão correlacionadas com a mobilidade reduzida da região lombar e da maior amplitude de movimento da região torácica, que incluem flexão e extensão no plano medial, flexão lateral no plano horizontal e rotação (SISSON, 1986a; HAUSSLER, 1999a; DENOIX e DYSON, 2003).

Os corpos vertebrais são estabilizados por articulações compostas por um disco intervertebral fibroso e dois ligamentos longitudinais. O ligamento longitudinal ventral localiza-se na superfície ventral dos corpos das vértebras e dos discos intervertebrais (Figura 3), onde está firmemente inserido. É substituído pelo músculo longo do pescoço na região torácica cranial. O ligamento longitudinal dorsal se localiza no assoalho do canal vertebral do áxis até o sacro, e está aderido à borda dorsal dos discos intervertebrais (SISSON, 1986a; HAUSSLER, 1999a; DENOIX e DYSON, 2003).

Os músculos epaxiais, situados dorsalmente ao eixo vertebral, são responsáveis pela dorsoflexão quando contraídos bilateralmente. A contração unilateral gera uma flexão lateral e contribui para a rotação da coluna vertebral (TOWNSEND, LEACH e FRETZ, 1983; SISSON, 1986b; DENOIX, 1987; DENOIX, 1999a; HAUSSLER, 1999a; DENOIX e AUDIGIÉ, 2001; DENOIX e DYSON, 2003).

Os músculos epaxiais incluem o espinhoso, o longo dorsal, o iliocostal e o multífidus (Figura 3). O músculo longo dorsal é o músculo mais forte. O músculo iliocostal é menor, mas desempenha um papel importante na flexão lateral devido a sua localização excêntrica. Caudalmente, esses músculos se fundem para formar o músculo eretor espinhal. O músculo multífidus se localiza sob o músculo espinhoso e está em contato direto com as vértebras. Este músculo desempenha um grande papel na estabilidade e propriocepção 
MENDES, A.B. et al. Lombalgia equina: diagnóstico e tratamento. PUBVET, Londrina, V. 7, N. 17, Ed. 240, Art. 1583, Setembro, 2013.

vertebral (SISSON, 1986b; HAUSSLER, 1999a; DENOIX e AUDIGIÉ, 2001; DENOIX e DYSON, 2003).

Os músculos hipaxiais, situados ventralmente ao eixo vertebral, são responsáveis pela ventroflexão quando contraídos bilateralmente. A contração unilateral induz á flexão lateral e contribui para a rotação (TOWNSEND, LEACH e FRETZ, 1983; SISSON, 1986b; DENOIX, 1987; DENOIX 1999a; HAUSSLER, 1999a; DENOIX e AUDIGIÉ, 2001; DENOIX e DYSON, 2003).

Os músculos hipaxiais incluem o psoas menor e o maior, o reto abdominal e os oblíquos abdominais (Figura 3). Os músculos psoas menor e maior se inserem na face ventral das vértebras lombares, sob os processos transversos, e das três últimas torácicas. Eles agem principalmente na articulação lombossacra, mas também agem sobre a articulação toracolombar e coluna lombar. 0 músculo reto abdominal age na ventroflexão de toda a coluna vertebral, devido a sua inserção no púbis, esterno e porção ventral das costelas. Os músculos oblíquos abdominais podem promover flexão lateral e rotação na coluna toracolombar, devido à sua inserção na tuberosidade coxal e costelas (TOWNSEND, LEACH e FRETZ, 1983; DENOIX, 1987; HAUSSLER, 1999a; DENOIX e AUDIGIÉ, 2001; DENOIX e DYSON, 2003).

\subsection{Diagnóstico}

\subsubsection{Exame clínico}

Os objetivos do exame clínico da região toracolombar dos equinos são: determinar se a dor está presente, sua localização e a possível causa (DENOIX e DYSON, 2003; HAUSSLER, 2007). 
MENDES, A.B. et al. Lombalgia equina: diagnóstico e tratamento. PUBVET, Londrina, V. 7, N. 17, Ed. 240, Art. 1583, Setembro, 2013.

\subsubsection{Exame físico}

O primeiro passo do exame físico é a visualização do animal em repouso. Para isso, o cavalo deve estar relaxado e adaptado ao local do exame. Além disso, deve permanecer em apoio quadrupedal sobre uma superfície lisa e plana (MARTIN JÚNIOR e KLIDE, 1999; DENOIX e DYSON, 2003; STASHAK, 2006).

O exame inicialmente é realizado observando o animal à distância e, depois, mais próximo. É importante avaliar a condição corpórea do cavalo, sua atitude, simetria muscular, conformação e o deslocamento e direcionamento do peso (MARTIN JÚNIOR e KLIDE, 1999; STASHAK, 2006).

\section{- Inspeção}

Primeiramente deve-se inspecionar o alinhamento da coluna vertebral. No equino, as curvaturas anormais mais comuns são a cifose lombar e a lordose torácica, podendo acometer o animal simultaneamente (DENOIX e DYSON, 2003; HAUSSLER, 2007).

A atrofia dos músculos epaxiais na região lombossacra implica na proeminência dos processos espinhosos, resultando em uma aparência cifótica da coluna lombar. A identificação de atrofia dos músculos epaxiais é um dos sinais de um animal potencialmente portador de lesões toracolombares, já que a atrofia reflete a redução de movimento em áreas de dor (DENOIX e DYSON, 2003). Áreas de edema ou falhas de pelos também devem ser investigadas. Quando presentes na região da sela indicam um mau ajuste da sela no animal ou uma má posição do cavaleiro sobre o animal (MARTIN JÚNIOR e KLIDE, 1999; DENOIX e DYSON, 2003; LANDMAN et al., 2004; DESBROSSE e VANDEWEERD, 2006; DYSON, 2007). 
MENDES, A.B. et al. Lombalgia equina: diagnóstico e tratamento. PUBVET, Londrina, V. 7, N. 17, Ed. 240, Art. 1583, Setembro, 2013.

\section{- Palpação}

A palpação deve ser realizada com o animal tranquilo, adaptado a presença e ao toque do examinador, para evitar falsas reações de dor (STASHAK, 2006). Os locais de palpação toracolombar são a linha média dorsal, onde se avalia o ligamento supraespinhoso, quanto à presença de massas, lacerações, fibroses, aumento de volume local e sensibilidade dolorosa, e a região paravertebral, para avaliação da musculatura epaxial, quanto a presença de alterações de tonicidade, temperatura, fasciculações e dor (FONSECA et al., 2006; HAUSSLER, 2007).

De uma maneira geral, se inicia a palpação aplicando-se uma pressão leve sobre as estruturas superficiais, o que auxilia na identificação de desmite supraespinhosa e má formação ou mau alinhamento dos processos espinhosos (DENOIX e DYSON, 2003; STASHAK, 2006). A palpação de estruturas profundas, como dos músculos epaxiais, deve ser realizada aplicando-se mais pressão (MARTIN JÚNIOR e KLIDE, 1999; STASHAK, 2006). O tamanho dos músculos epaxiais impossibilita a palpação das articulações intervertebrais dorsais e processos transversos (DENOIX e DYSON, 2003).

De acordo com Stashak (2006), um sinal positivo de dor é obtido quando o cavalo se encolhe e evidencia-se o espasmo muscular sobre o local da lesão. Alguns cavalos demonstram uma resposta mais dramática, emitindo gemidos, escoiceando e, até mesmo, fugindo do exame ao se recuar quando a pressão é exercida.

A palpação transretal pode ser utilizada para identificar dor nas estruturas profundas, como músculos hipaxiais e corpos vertebrais, da região lombar. Porém, esse procedimento não é rotineiramente realizado no exame físico da coluna toracolombar. Um exame retal permite a palpação dos músculos hipaxiais, além de outros tecidos moles da região pélvica. Também são 
MENDES, A.B. et al. Lombalgia equina: diagnóstico e tratamento. PUBVET, Londrina, V. 7, N. 17, Ed. 240, Art. 1583, Setembro, 2013.

palpados os corpos vertebrais, que podem ser uma fonte de dor primária (DESBROSSE e VANDEWEERD, 2006).

- Testes de mobilidade

A estimulação da mobilidade da coluna vertebral toracolombar é importante para se avaliar a quantidade de movimento permitida pelo equino e para observar manifestações de dor à movimentação, como tensão da musculatura toracolombar, movimentos de cauda, flexão dos membros, alteração de comportamento e o tempo para retornar a posição de equilíbrio ou de relaxamento do animal (MARTIN JÚNIOR e KLIDE, 1999; DENOIX e DYSON, 2003; FONSECA, 2005; STASHAK, 2006; HAUSSLER, 2007; VAN WESSUM, 2009). Durante a realização do teste busca-se analisar a amplitude de flexão dorsal, ventral, lateral e movimento de rotação tolerada pelo paciente e pesquisar a existência de um foco de dor ao nível vertebral ou lesões em tecidos moles paravertebrais (FONSECA, 2008).

O seguinte protocolo foi sugerido por Denoix e Dyson (2003) e Fonseca (2005): (1) ventroflexão e dorsoflexão torácica e lombar; (2) flexão lateral e rotação toracolombar; e (3) flexão lateral e rotação cervical e torácica. A dorsoflexão é estimulada pela pressão digital na altura de T10, T14 ou na articulação lombossacra. Já a ventroflexão pode ser induzida pela pressão digital na base da cauda ou na cartilagem xifóide. A lateroflexão pode ser obtida pela pressão simultânea na tuberosidade isquiática e gradil costal ou pelo deslizamento de um objeto de ponta romba no músculo longo dorsal, no sentido craniocaudal na região paravertebral. O movimento de rotação da coluna é realizado quando a lateroflexão é estimulada, desse modo, estes dois movimentos são avaliados em conjunto (FONSECA, 2005). 
MENDES, A.B. et al. Lombalgia equina: diagnóstico e tratamento. PUBVET, Londrina, V. 7, N. 17, Ed. 240, Art. 1583, Setembro, 2013.

\section{- Exame durante o movimento}

A avaliação do animal ao passo, trote e galope é essencial para se identificar a presença de dor e alterações funcionais. O animal deve ser examinado em movimentos em linha reta e em círculos ao passo e trote em piso duro, e ao trote e galope em piso macio para a identificação de alterações de mobilidade (DENOIX e DYSON, 2003; STASHAK, 2006).

Durante o exercício, observa-se se existe uma rigidez do dorso, principalmente quando o animal é forçado a virar, bruscamente, de um lado para o outro. A lombalgia também pode influenciar na amplitude e arco do passo, resultando em um andamento mais rígido. Em piso macio, o animal mostra uma perda do balanço e uma tendência a direcionar o corpo na direção oposta ao círculo (DENOIX e DYSON, 2003; STASHAK, 2006).

Muitas vezes pode-se diagnosticar uma claudicação de membros pélvicos juntamente com um problema na coluna vertebral (SCHOEN, 2000; DESBROSSE e VANDEWEERD, 2006; VAN WESSUM, 2009). Lesão em membros pélvicos pode causar uma alteração na elevação do membro afetado e anormalidades na marcha, isso, posteriormente, causa injúrias devido o excesso de trabalho da musculatura dos membros torácicos e da musculatura paravertebral. Da mesma forma, lesões na coluna vertebral podem produzir anormalidades na marcha e sobrecarga de trabalho dos membros, levando a claudicação dos membros pélvicos (HAUSSLER, 2000; DYSON, 2007). 
MENDES, A.B. et al. Lombalgia equina: diagnóstico e tratamento. PUBVET, Londrina, V. 7, N. 17, Ed. 240, Art. 1583, Setembro, 2013.

2.3 Principais lesões que acometem a coluna toracolombar dos equinos

2.3.1 Contato ou sobreposição dos processos espinhosos ("kissing spines")

É uma condição congênita ou adquirida, caracterizada por uma orientação anormal dos processos espinhosos (DENOIX e DYSON, 2003). É a enfermidade mais conhecida da região toracolombar do equino, sendo relatada como a causa mais comum de dor lombar. Animais da raça Puro Sangue Inglês tem maior tendência a apresentar este tipo de lesão, quando comparados a equinos de outras raças, pois apresentam processos espinhosos mais longos e espaços interespinhosos mais estreitos (HAUSSLER, 1999b; HENDRICKSON, 2006a).

A localização mais comum de ocorrência deste tipo de lesão é no segmento entre T10 e T18, onde o peso do cavaleiro é mais concentrado e os espaços interespinhais são mais estreitos (HAUSSLER, 1999b; WEAVER, JEFFCOTT e NOWAK, 1999; DENOIX e DYSON, 2003; HENDRICKSON, 2006a).

Clinicamente, o paciente não demonstra claudicação, mas apresenta dor a palpação da coluna, manifestada pela ventroflexão quando o local da lesão é palpado. Além disso, o animal recusa a dorsoflexão e a lateroflexão, demonstrando rigidez e agitação (TURNER, 2003).

O diagnóstico é feito por meio de bloqueios anestésicos, radiografia e ultrasonografia, sendo estes avaliados em conjunto com o exame físico (HAUSSLER, 1999b; DENOIX e DYSON, 2003; FONSECA et al., 2006).

O bloqueio anestésico promove alívio da dor, porém, geralmente não identifica o local exato da lesão. Desse modo, essa técnica diagnóstica deve ser usada em associação com as demais (HENDRICKSON, 2006a; MITCHELL, 2009). A radiografia dos nos leves demonstra estreitamento do espaço interespinhoso, 
MENDES, A.B. et al. Lombalgia equina: diagnóstico e tratamento. PUBVET, Londrina, V. 7, N. 17, Ed. 240, Art. 1583, Setembro, 2013.

geralmente com esclerose das bordas dos processos adjacentes. Já em casos graves, o exame radiográfico mostra remodelação das bordas cranial e caudal, e esclerose subcortical das margens dos processos espinhosos (Figura 4) (WEAVER, JEFFCOTT e NOWAK, 1999; MITCHELL, 2009). Através do exame ultra-sonográfico pode-se visualizar contato ou remodelamento entre dois processos espinhosos adjacentes, adelgaçamento transversal, alinhamento anormal dos processos e, fraturas, principalmente na região da cernelha (FONSECA et al., 2006; MITCHELL, 2009).

O prognóstico dos animais que apresentam contato ou sobreposição dos processos espinhosos é reservado (DENOIX e DYSON, 2003; HENDRICKSON, 2006a).

\subsubsection{Desmite supraespinhosa}

Desmite consiste em uma inflamação ligamentar, que está diretamente relacionada a excesso de estresse físico (GILLIS, 1999; VALBERG, 1999).

Lesões do ligamento supraespinhoso ocorrem comumente entre T15 e L3. Uma vez lesado, o ligamento perde suas características de resistência e elasticidade, assim como os pontos de inserção destes nos processos espinhosos se tornam frágeis, diminuindo a estabilidade vertebral (FONSECA et al., 2006).

Os principais achados no exame físico são: aumento de volume localizado, sensibilidade dolorosa à palpação da região paramediana e redução da amplitude de ventroflexão e lateroflexão. Além disso, durante o exame em movimento, observa-se contração abdominal, movimento cervical dorsal e, quando examinado ao galope, o animal tenta sair do círculo (FONSECA, 2008). 
MENDES, A.B. et al. Lombalgia equina: diagnóstico e tratamento. PUBVET, Londrina, V. 7, N. 17, Ed. 240, Art. 1583, Setembro, 2013.

Estas lesões são facilmente identificadas através da ultra-sonografia (Figura 5). Ocorrem geralmente no aspecto dorsal dos processos espinhosos, podendo se estender entre dois processos adjacentes (DENOIX, 1999b; DENOIX e DYSON, 2003). Lesões hipoecóicas no ligamento são compatíveis com desmites agudas, e as lesões hiperecóicos, com ou sem sombras acústicas, podem ser observadas em casos de desmites crônicas. A desmite de inserção, também denominada de entesopatia, pode ser identificada como irregularidades na superfície dorsal dos processos espinhosos (DENOIX, 1999b; GILLIS, 1999; REEF, 1998; DENOIX e DYSON, 2003).

A termografia também é bastante útil no diagnóstico de desmites, revelando alterações fisiológicas, antes que elas apareçam como sinais clínicos ou como anormalidades ultra-sonofráficas ou radiográficas. Sendo assim, ao exame termográfico, as desmites são visualizadas como manchas quentes, que significam elevação da temperatura local, ocasionada por processos inflamatórios (TURNER, 1998; VON SCHWEINITZ, 1999; EDDY, VAN HOOGMOED, e SNYDER, 2001; TURNER, PANSCH e WILSON, 2001).

Equinos que apresentam desmite supraespinhosa possuem um prognóstico bom (DENOIX e DYSON, 2003; HENDRICKSON, 2006a).

2.3.3 Osteoartrite dos processos articulares (osteoartrite intervertebral dorsal)

É definida como uma condição crônica, cuja principal característica é a degeneração articular (HAUSSLER, 1999b). Segundo Denoix (1999b), a osteoartrite dos processos articulares é uma das lesões mais comuns associadas à lombalgia, fato confirmado em estudo sobre a lombalgia em equinos atletas da raça Quarto de Milha, no qual Fonseca et al. (2006) relataram que a osteoartrite do processo articular foi a enfermidade com a 
MENDES, A.B. et al. Lombalgia equina: diagnóstico e tratamento. PUBVET, Londrina, V. 7, N. 17, Ed. 240, Art. 1583, Setembro, 2013.

segunda maior ocorrência. De acordo com outro estudo, realizado por Hendrickson (2006a), a osteoartrite dos processos articulares foi encontrada em $97 \%$ dos 36 equinos Puro Sangue Inglês examinados.

Clinicamente, observa-se dor na musculatura epaxial, principalmente lombar, diminuição da amplitude de movimento da articulação lombossacra, tensão da musculatura abdominal e diminuição da amplitude da passada dos membros pélvicos (ALVES et al., 2007).

Segundo Denoix e Dyson (2003), a osteoartrite dos processos articulares pode ser facilmente diagnosticada através da radiografia (Figura 6). Os achados radiográficos são encontrados na maioria das vezes nas regiões toracolombar caudal e lombar. Isto se deve ao fato de que os processos articulares nestes locais possuem uma superfície côncava e uma convexa, o que contribui para um acentuado estresse articular durante a realização dos diversos movimentos da coluna (DENOIX, 1999b; GIRODROUX, DYSON e MURRAY, 2009). Os achados radiográficos, frequentemente, associados à osteoartrite dos processos articulares nos equinos são: assimetria dos processos articulares, esclerose do osso subcondral, proliferação intra e periarticular, anquilose, osteólise de articulações intervertebrais e fraturas (DENOIX e DYSON, 2003; GIRODROUX, DYSON e MURRAY, 2009).

No exame ultra-sonográfico das articulações intervertebrais dorsais, acometidas por osteoartrite, observa-se proliferações periarticulares, irregularidade dos processos articulares, com perda de espaço articular (Figura 7), áreas de reabsorção óssea e fraturas (DENOIX e DYSON, 2003). O exame termográfico pode ser útil na identificação da osteoartrite dos processos espinhoso, pois demonstra imagens caracterizadas por manchas frias, causadas pelo fluxo sanguíneo diminuído, devido às alterações no tônus vasomotor, provocado principalmente por síndromes de dor crônica (TURNER, 
MENDES, A.B. et al. Lombalgia equina: diagnóstico e tratamento. PUBVET, Londrina, V. 7, N. 17, Ed. 240, Art. 1583, Setembro, 2013.

1998; VON SCHWEINITZ, 1999; EDDY, VAN HOOGMOED e SNYDER 2001; TURNER, PANSCH e WILSON, 2001).

O prognóstico para os animais, que possuem osteoartrite dos processos articulares, é ruim (DENOIX, 1999b; DENOIX e DYSON, 2003; HENDRICKSON, 2006a; GIRODROUX, DYSON e MURRAY, 2009).

\subsubsection{Lesões de corpo vertebral}

Lesões de corpo vertebral são incomuns em equinos, sendo diagnosticadas preferencialmente através da radiografia, já que essas lesões não podem ser observadas pela ultra-sonografia da região toracolombar, a não ser a partir de L4, por acesso transretal (DENOIX, 1999b; HAUSSLER, 1999c).

Segundo Denoix e Dyson (2003) os achados radiográficos das lesões de corpos vertebrais incluem: espondilose vertebral (Figura 8), que consiste em proliferações ventrais, ventrolaterais ou laterais, que ocorrem geralmente na região torácica média; deformações do corpo vertebral das vértebras torácicas caudais; e entesopatia de disco. Geralmente essas lesões são diagnosticadas em animais com histórico ou manifestações clínicas de lombalgia aguda, intermitente ou crônica. Entretanto, também podem ser identificadas em animais sem sinais clínicos ou histórico de dor lombar, como no caso de equinos com espondilose (HAUSSLER, 1999c; DENOIX e DYSON, 2003).

Fraturas e luxações das vértebras lombares geralmente resultam em sinais neurológicos, além disso, podem ocorrer sinais de dor aguda, com rápida atrofia da musculatura epaxial, porém, a ataxia pode não ser evidente (HAUSSLER, 1999c; DENOIX e DYSON, 2003).

O prognóstico nos casos de espondilose vertebral varia muito, de acordo com a tolerância do paciente, mas comumente se observa que o prognóstico é pior 
MENDES, A.B. et al. Lombalgia equina: diagnóstico e tratamento. PUBVET, Londrina, V. 7, N. 17, Ed. 240, Art. 1583, Setembro, 2013.

quanto maior for o número de vértebras acometidas (DENOIX e DYSON, 2003; HENDRICKSON, 2006a).

\subsubsection{Miosite}

É o processo inflamatório que acomete os músculos esqueléticos, podendo ser causado devido a traumas durante grandes esforços de contração e extensão de grupos musculares. A miosite pode ainda ser uma forma de cansaço ou fadiga muscular (HENDRICKSON, 2006b).

Os sinais clínicos associados às enfermidades da musculatura toracolombar incluem atrofia uni ou bilateral, dor à palpação, edema focal, consistência aumentada ou diminuída da musculatura epaxial. Outros sinais incluem rigidez da coluna vertebral, baixo desempenho, alteração de comportamento, dificuldade de aceitar a sela, passada larga, galope encurtado e claudicação dos membros pélvicos (VALBERG, 1999; HENDRICKSON, 2006b).

A ultra-sonografia é uma importante ferramenta para o diagnóstico final da lesão, seja ela aguda ou crônica, juntamente com as biópsias musculares e os exames bioquímicos (VALBERG, 1999; HENDRICKSON, 2006b). A termografia também é bastante útil no diagnóstico de lesões musculares, identificando áreas de atrofia, assimetria e espasmos musculares (VON SCHWEINITZ, 1999).

O prognóstico pode ser reservado em casos em que um diagnóstico não foi estabelecido ou quando houver doença muscular generalizada. Mas, no geral, os animais se recuperam totalmente (HENDRICKSON, 2006b).

\subsection{Tratamento}

O tratamento das enfermidades toracolombares em equinos atletas é controverso, devido ao fato de que o diagnóstico é pouco realizado e as 
MENDES, A.B. et al. Lombalgia equina: diagnóstico e tratamento. PUBVET, Londrina, V. 7, N. 17, Ed. 240, Art. 1583, Setembro, 2013.

recomendações terapêuticas são na maioria das vezes conservadoras e não específicas (HAUSSLER, 2007).

Uma variedade de medidas terapêuticas é recomendada, incluindo antiinflamatórios não esteróides sistêmicos, infiltrações locais com corticóides associados ou não a neurolíticos, acupuntura, quiropraxia, fisioterapia, modificações no treinamento, além de procedimentos cirúrgicos (HAUSSLER, 1999a; DENOIX e DYSON, 2003; TURNER, 2003).

O objetivo do tratamento é eliminar a dor do paciente, permitindo que ele possa ser exercitado, evitando assim, a perda de massa muscular e de condicionamento físico (DENOIX e DYSON, 2003).

\subsubsection{Tratamento sistêmico}

Antiinflamatórios não esteroidais como o flunixin meglumine $(1,1 \mathrm{mg} / \mathrm{kg} ; \mathrm{IV}$; a cada 24 horas [SID]); cetoprofeno $(2,2 \mathrm{mg} / \mathrm{kg} ;$ PO; SID) ou fenilbutazona (2,2 a 4,4 mg/kg; IV; SID), são indicados para promover alívio da dor (MARKS, 1999; DENOIX e DYSON, 2003; DENOIX et al. 2005; DENOIX e AGRÉGÉ, 2008; MITCHELL, 2009).

Miorrelaxantes, como o metocarbamol ( 5 a $25 \mathrm{mg} / \mathrm{kg}$; IV; SID), são indicados em animais que apresentam espasmos da musculatura toracolombar (MARKS, 1999; DENOIX e DYSON, 2003; MITCHELL, 2009).

Atualmente tem-se recomendado o tiludronato, quando lesões ósseas são diagnosticadas, principalmente envolvendo articulações intertransversas. Esse fármaco deve ser administrado por via intravenosa, lentamente durante 30 minutos, em uma única dose total de $1 \mathrm{mg} / \mathrm{kg}$ (DENOIX, AUDIGIÉ e COUDRY, 2005; DENOIX e AGRÉGÉ, 2008; MITCHELL, 2009). O tiludronato é um composto biofosfonato, que pode ser útil em situações com intensa 
MENDES, A.B. et al. Lombalgia equina: diagnóstico e tratamento. PUBVET, Londrina, V. 7, N. 17, Ed. 240, Art. 1583, Setembro, 2013.

remodelação óssea, pois tem a capacidade de inibir a reabsorção óssea mediada pelos osteoclastos (DENOIX, 2009).

\subsubsection{Infiltrações locais}

Infiltrações paraespinhais ou interespinhais de corticosteróides (acetato de metilprednisolona $40 \mathrm{mg} /$ ponto de injeção), associadas ou não a miorrelaxantes ou neurolíticos ( $2 \mathrm{ml}$ de ${ }^{1}$ Sarapin ${ }^{\circledR} /$ ponto de injeção), são utilizadas no tratamento de sobreposição dos processos espinhosos e desmites inter e supraespinhosas, para redução da dor. Nesses casos, deve-se utilizar agulhas de 4 a $5 \mathrm{~cm}$ de comprimento, para injetar o fármaco no músculo longo dorsal ou no espaço interespinhoso (DENOIX e DYSON, 2003; DENOIX et al. 2005; FONSECA et al., 2006; DENOIX e AGRÉGÉ, 2008; MITCHELL, 2009).

No caso de osteoartrite dos processos articulares, a infiltração deve ser no músculo multífidus de ambos os lados, guiada por ultra-som e realizada na região paramediana. Neurolíticos são contra indicados devido à proximidade dos ramos dos nervos espinhais (DENOIX e DYSON, 2003; DENOIX, AUDIGIÉ e COUDRY, 2005; DENOIX e AGRÉGÉ, 2008; MITCHELL, 2009).

\subsubsection{Terapias alternativas}

\subsubsection{Acupuntura}

A acupuntura vem sendo relatada como uma prática efetiva no tratamento de lombalgias causadas por lesões em tecidos ou vértebras da região toracolombar, podendo ser utilizada sozinha ou em associação com outras terapias (MERRIAN, 1997; ALTMAN, 1998; RIDGWAY, 1999; SCHOEN, 2000 e 2003; MARTIN JÚNIOR e KLIDE, 2006).

\footnotetext{
${ }^{1} \operatorname{Sarapin}^{\circledR}$ (extrato de sarracenia purpúrea; álcool benzílico 0,75\%; cloruto de amônia 0,5\%) - High Chemical Company
} 
MENDES, A.B. et al. Lombalgia equina: diagnóstico e tratamento. PUBVET, Londrina, V. 7, N. 17, Ed. 240, Art. 1583, Setembro, 2013.

Acupuntura consiste na inserção de finas agulhas em locais específicos, para a produção do efeito terapêutico (ALTMAN, 1998; SCHOEN, 2000 e 2003). As modalidades de acupuntura que podem ser utilizadas no tratamento das lombalgias incluem a utilização de agulhas, a eletroacupuntura e a aquapuntura (ALTMAN, 1998; RIDGWAY, 1999; SCHOEN, 2000 e 2003; MARTIN JÚNIOR e KLIDE, 2006; HAUSSLER, 2007).

O principal benefício da acupuntura em caso de lombalgia é a redução da dor via liberação de endorfinas (FLEMING, 1998). O alívio da dor muitas vezes é imediato, mas a duração pode ser variável, dependendo do tipo e severidade das lesões. As lesões agudas geralmente respondem rapidamente e exigem menos sessões de tratamento, ao passo que lesões crônicas podem necessitar de tratamentos periódicos ou a longo prazo (HAUSSLER, 2007).

\subsubsection{Quiropraxia}

A quiropraxia é uma forma de terapia manual que consiste na indução de um movimento vertebral substancial, geralmente além do movimento de extensão normal que ocorre durante a locomoção, através da aplicação de forças controladas em articulações específicas ou regiões anatômicas para produzir uma resposta terapêutica (HAUSSLER, 1999c e 2000).

A quiropraxia consiste na localização de disfunções vertebrais que são caracterizadas por dores musculares localizadas, hipertonicidade muscular e mobilidade articular restrita. Sendo assim, o objetivo da quiropraxia é estimular reflexos neurológicos, restaurar a mobilidade articular e, promover alívio da dor e relaxamento muscular (HAUSSLER, 2007).

A quiropraxia deve ser realizada por médicos veterinários especializados, podendo ser utilizada de maneira complementar no diagnóstico, tratamento e prevenção de lesões musculoesqueléticas relacionadas ao baixo desempenho 
MENDES, A.B. et al. Lombalgia equina: diagnóstico e tratamento. PUBVET, Londrina, V. 7, N. 17, Ed. 240, Art. 1583, Setembro, 2013.

atlético. No entanto é mais eficaz no estágio inicial da doença, sendo contra indicada na fase aguda das lesões de tecidos moles (HAUSSLER, 2000; HENDRICKSON, 2006; HAUSSLER, 2007).

\subsubsection{Fisioterapia}

A fisioterapia tem com objetivo restaurar a adequada movimentação do cavalo num curto período de tempo após a injúria tecidual, auxiliando os animais no retorno às atividades físicas e atléticas (RIDGWAY e HARMAN, 1999; BROMILEY, 1999 e 2000; BALL, 2003a; HAUSSLER, 2007).

\section{- Estimulação elétrica}

A estimulação elétrica é definida como a aplicação de corrente elétrica de baixa frequência diretamente sobre a área lesada, sendo seus principais benefícios, 0 alívio da dor e o fortalecimento muscular (POTER, 2005). Existem, basicamente, dois tipos de estimulação elétrica, o TENS (trascutaneal electrical nerve stimulation) e o FES (functional electrial stimulation). O TENS é tem a finalidade de promover analgesia através do bloqueio da transmissão dos sinais de dor por meio da liberação de endorfinas. O FES tem o objetivo de estimular nervos motores a produzir a contração, a fim de evitar a atrofia muscular (BROMILEY, 1999 e 2000; BALL, 2003b; PORTER, 2005; BUCHNER e SCHILDBOECK, 2006; CANAPP, 2007; PORTER, 2009; SCHILS, 2009).

\section{- Fototerapia}

A fototerapia é uma forma de energia eletromagnética, de baixa densidade, que atua em tecidos mais superficiais, estimulando a liberação de neurotransmissores, os quais ativam as funções celulares sem elevar a temperatura do tecido. A energia é usada para estimular a cicatrização, reduzir a dor e aumentar a circulação sanguínea e linfática. A fototerapia pode ser 
MENDES, A.B. et al. Lombalgia equina: diagnóstico e tratamento. PUBVET, Londrina, V. 7, N. 17, Ed. 240, Art. 1583, Setembro, 2013.

usada tanto em lesões agudas quanto crônicas, desse modo, pode ser usada no tratamento das enfermidades toracolombares com a finalidade de reduzir o processo inflamatório, promover alívio da dor, relaxar espasmos musculares, diminuir a tensão muscular, melhorando, desse modo, a amplitude de movimento da coluna vertebral (BALL, 2003b; PORTER, 2005; CANAPP, 2007; PORTER, 2009).

- Ultra-som terapêutico

O ultra-som terapêutico é uma forma de energia acústica que atua como um agente aquecedor de tecidos profundos, amplamente utilizado no tratamento de doenças musculoesqueléticas. Os efeitos do ultra-som terapêutico podem ser divididos em térmicos e atérmicos. Os efeitos térmicos incluem aumento do fluxo sanguíneo na região de tratamento, alívio da dor, redução do espasmo muscular, aumento da extensibilidade tecidual e redução do processo inflamatório. Já os efeitos atérmicos incluem modulação do reparo ósseo e organização de processos cicatriciais (BALL, 2003b; PORTER, 2005; BUCHNER e SCHILDBOECK, 2006; CANAPP, 2007; PORTER, 2009).

\section{- Massagem}

A massagem consiste na manipulação de tecidos moles para fins terapêuticos utilizando diversas técnicas, as quais permitem relaxamento muscular, aumento da circulação, fortalecimento do tônus muscular e alívio da dor (DENOIX e PAILLOUX, 1996; BALL, 2003a; HARMAN, 2003). As técnicas de massagem podem ser usadas para tratar lesões musculares específicas, prevenir injúrias e promover o aquecimento dos animais antes do treinamento, diminuindo as chances de estiramento durante o exercício (DENOIX e PAILLOUX, 1996; HARMAN, 2003). 
MENDES, A.B. et al. Lombalgia equina: diagnóstico e tratamento. PUBVET, Londrina, V. 7, N. 17, Ed. 240, Art. 1583, Setembro, 2013.

\section{- Alongamento}

O alongamento pode ser usado como forma de reabilitação de uma lesão ou como forma de prevenção de futuras lesões. O princípio do alongamento tem como função reduzir a tensão muscular e aumentar a elasticidade e flexibilidade dos músculos, tendões e ligamentos, reduzindo as chances de estiramentos durante o exercício. Além disto, ele também alivia a dor causada por espasmos musculares e lesões, e atua na propriocepção, facilitando a coordenação e equilíbrio (HARMAN, 2003).

- Ondas de choque extracorpóreas

As ondas de choque extracorpóreas são ondas de pressão acústica produzidas por um gerador e propagadas no tecido acometido, onde exercerão seus efeitos (MCCLURE, VAN SICKLE e WHITE, 2000; MCCLURE et al., 2003). Recentes estudos avaliaram os efeitos das ondas de choque em tendões e ligamentos, e evidenciaram que estas induzem neovascularização na inserção tendínea e ligamentar, o que pode diminuir a dor e aumentar o reparo tecidual (MCCLURE, 2009).

Alves et al. (2009) constataram, através de experimento, que tanto as desmites agudas quanto as crônicas responderam de maneira satisfatória à terapia por ondas de choque extracorpóreas, havendo remodelação das fibras do ligamento nos locais afetados.

Em casos de osteoartrite, a terapia por ondas de choque extracorpórea, promove osteogênese e remodelamento ósseo, retardando o processo degenerativo (MCCARROL e MCCLURE, 2000; FRISBIE, KAWCAK e MCILWRAITH, 2004). 
MENDES, A.B. et al. Lombalgia equina: diagnóstico e tratamento. PUBVET, Londrina, V. 7, N. 17, Ed. 240, Art. 1583, Setembro, 2013.

\subsubsection{Modificações no treinamento}

Os objetivos desta modificação são evitar a atrofia muscular e desenvolver o controle proprioceptivo toracolombar e estabilidade vertebral por meio de exercícios controlados. O descanso é contra indicado, exceto em animais irresponsivos ao tratamento (DENOIX e DYSON, 2003; DENOIX et al. 2005; DENOIX e AGRÉGÉ, 2008).

\subsubsection{Tratamento cirúrgico}

O tratamento cirúrgico é realizado com sucesso nos casos de sobreposição dos processos espinhosos, através da ressecção das tuberosidades dos processos espinhosos, em animais irresponsivos ao tratamento conservativo dessa lesão. Entretanto, a cirurgia é feita somente em animais com lesões envolvendo apenas a porção dorsal dos processos espinhosos. Um repouso de seis meses é necessário de maneira geral, após o procedimento cirúrgico (DENOIX e DYSON, 2003).

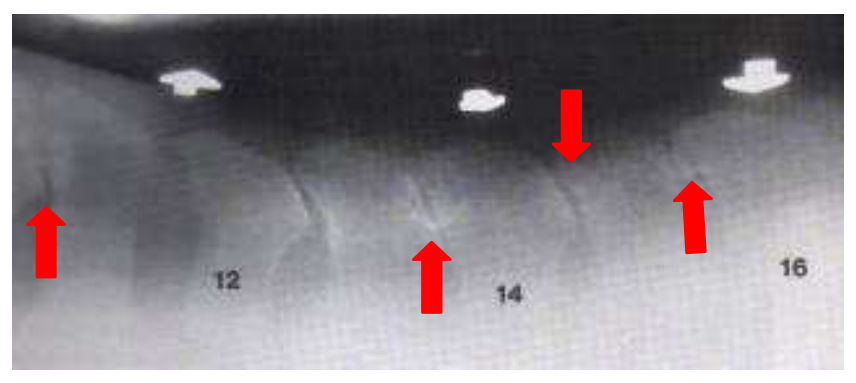

Figura 4. Vista lateral da vértebra $\mathrm{T} 10$ até a vértebra T16 de um cavalo de 4 anos de idade apresentando um histórico de lombalgia crônica. Observa-se, na ponta das setas vermelhas, a sobreposição dos processos espinhosos das vértebras T10 e T11, e das vértebras de T13 até T16 (BUTLER et al., 2002). 


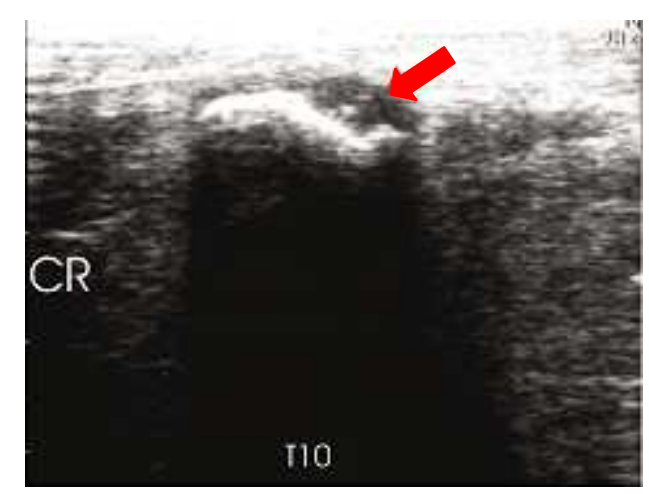

Figura 5. Imagem ultra-sonográfica da desmite supraespinhosa, caracterizada por um foco anecóico no ligamento e uma área de irregularidade na extremidade dorsal do processo espinhoso associado ao ligamento lesionado (seta). CR- cranial (FONSECA et al., 2006).

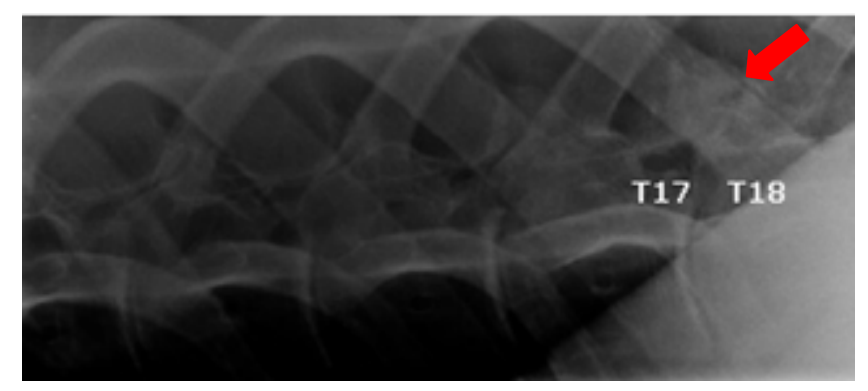

Figura 6. Vista oblíqua-lateral esquerda das faces articulares da região torácica caudal de um cavalo de adestramento de 7 anos de idade, com o histórico de relutância ao trabalho. Observe, na ponta da seta, a perda de espaço articular entre as vértebras T17 e T18 e esclerose do osso subcondral, o que significa osteoartrite avançada (DYSON, 2007). 
MENDES, A.B. et al. Lombalgia equina: diagnóstico e tratamento. PUBVET, Londrina, V. 7, N. 17, Ed. 240, Art. 1583, Setembro, 2013.

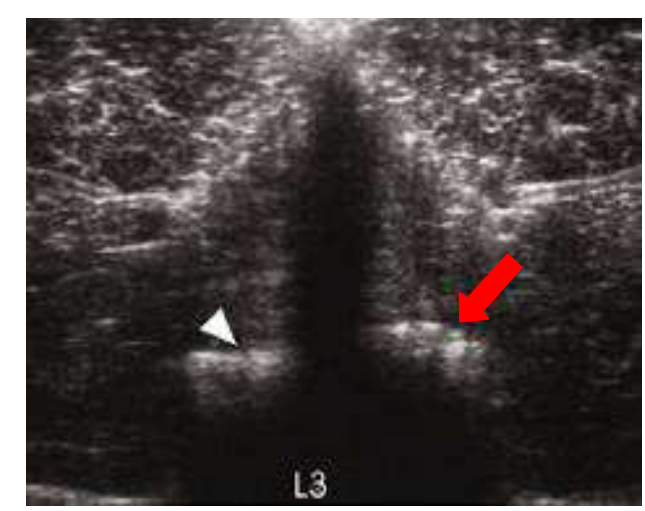

Figura 7. Imagem ultra-sonográfica da osteoartrite intervertebral dorsal, mostrando a irregularidade dos processos articulares cranial e caudal, com a perda de espaço articular. Espaço articular (seta branca); lesão (seta vermelha). Vista transversal (FONSECA et a., 2006).

Figura 8. Vista lateral da vértebra T10 até a vertebral T16 de um cavalo de 10 anos de idade, com histórico de queda de desempenho atlético. Observa-se, na ponta das setas, a espondilose envolvendo 0 aspecto ventral das vértebras T11 até T14 (DYSON, 2007). 
MENDES, A.B. et al. Lombalgia equina: diagnóstico e tratamento. PUBVET, Londrina, V. 7, N. 17, Ed. 240, Art. 1583, Setembro, 2013.

\section{Conclusão}

Por meio dessa revisão de literatura pode-se concluir que as lombalgias em equinos são uma causa importante para a queda de performance atlética, sendo assim o conhecimento da anatomia da região toracolombar é de fundamental importância para o exame semiológico da coluna vertebral dos equinos.

A elevada incidência de enfermidades toracolombares, o difícil diagnóstico e a importância desta região anatômica na locomoção dos cavalos, justificam as pesquisas relacionadas a lombalgia equina, principalmente direcionadas a uma melhor qualidade do diagnóstico e consequente inovações terapêuticas que resultem em menor tempo de afastamento das atividades esportivas.

\section{Referências bibliográficas}

ALTMAN, S. Small animal acupuncture: scientific basis and clinical applications In: SCHOEN, A. M.; WYNN, S. G. Complementary and alternative veterinary medicine: principles and practice. St. Louis: Mosby, 1998. p. 147-167.

ALVES, A. L. G.; FONSECA, B. P. A.; THOMASSIAN, A.; NICOLETTI, J. L. M.; HUSSNI, C. A.; SILVEIRA, A. B. Lombalgia em equinos. Braz. J. Vet. Res. Anim. Sci., São Paulo, v. 44, n. 3, p. 191-199, 2007.

ALVES A. L. G.; FONSECA, B. P. A.; NICOLETTI, J. L. M.; HUSSNI, C. A.; SOARES, L. V. Tratamento de desmite supra e interespinhosa em equinos utilizando a terapia por ondas de choque extracorpóreas. Vet. e Zootec., v. 16, n. 1, p. 143-151, 2009.

BALL, M. Therapeutic use of ultrasound, lasers, and electromagnetics. In: ROSS, M. W.; DYSON, S. J. Diagnosis and management of lameness in the horse. 1. ed. Philadelphia: Saunders, 2003a, p. 811-813.

BALL, M. Physical therapy and rehabilitation. In: ROSS, M. W.; DYSON, S. J. Diagnosis and management of lameness in the horse. 1. ed. Philadelphia: Saunders, 2003b, p. 817-818.

BROMILEY, M. W. Physical therapy for the equine back. Vet. Clin. North Am. Equine Pract., v.15, n.1, p. 223-246, 1999.

BROMILEY, M.W. Physical therapy in equine veterinary medicine: useful or useless? In: ANNUAL CONVENTION OF THE AMERICAN ASSOCIATION OF EQUINE PRACTIONERS, 46, 2000, San Antonio. Proccedings... Texas, USA, 2000. p. 94-97.

BUCHNER, H. H. F.; SCHILDBOECK, U. Physiotherapy applied to the horse: a review. Equine Vet. J. v. 38, n. 6, p. 574-580, 2006. 
BUTLER, J. A.; COLLES, C. M.; DYSON, S.; KOLD, S.; POULOS, P. Clinical radiology of the horse. 2. ed. Malden, Mass: Blackwell Science, 2002, 403-456.

CANAPP, D. A. Select modalities. Clinical Techniques in Small Animal Practice. p. 160$165,2007$.

DENOIX, J-M. Kinematics of the thoracolumbar spine in the horse during dorsoventral movements: A preliminary report. Equine Exercise Physiology, 2nd ICEEP Publications, 1987, p. 607-614.

DENOIX, J.M.; PAILLOUX, J.P. Physical therapy and massage for the horse. 2. ed. Vermont: Trafalgar Square, 1996, p. 276.

DENOIX, J-M. Spinal biomecanics and functional anatomy. Vet. Clin. North Am. Equine Pract., v. 15, n. 1, p. 27-60, 1999a.

DENOIX, J-M. Ultrasonographic evaluation of back lesions. Vet. Clin. North Am. Equine Pract., v. 15, n. 1, p. 131-159, 1999 b.

DENOIX, J-M.; AUDIGIÉ, F. The back and the neck. In: BACK, W.; CLAYTON, H. Equine Iocomotion. Philadelphia: Saunders, 2001. p. 167-192.

DENOIX, J-M.; DYSON, S. J. Thoracolumbar spine. In: ROSS, M. W.; DYSON, S. J. Diagnosis and management of lameness in the horse. 1. ed. Philadelphia: Saunders, 2003. p. 509521.

DENOIX, J.D.; AUDIGIÉ, F.; COUDRY, V. Review of diagnosis and treatment of lumbossacral pain in sport and race horses. In: ANNUAL CONVENTION OF THE AMERICAN ASSOCIATION OF EQUINE PRACTIONERS, 51, 2005, Seattle. Proceedings...Washington, USA, 2005. p. 366373.

DENOIX, J-M.; AGRÉGÉ, J. Diagnosis and treatment of lumbosacral and sacroiliac pain in horses. In: INTERNATIONAL CONGRESSO OF WORLD EQUINE VETERINARY ASSOCIATION, 2008. Proceedings... Moscow, Russia, 2008. p. 290-297.

DENOIX, J-M. Use of tiludronate (Tildren ${ }^{\circledR}$, Ceva Santé Animale) in horses. In: INTERNATIONAL CONGRESSO OF WORLD EQUINE VETERINARY ASSOCIATION, 2009, Guarujá. Proceedings... São Paulo, Brazil, 2009.

DESBROSSE, F.; VANDEWEERD, J.M., Back pain and lameness: a clinical approach to assess their relationship. In: INTERNATIONAL CONGRESSO OF WORLD EQUINE VETERINARY ASSOCIATION, 2006. Proceedings... Marrakech, Morocco, 2006. p. 51-56.

DYCE, K. M.; SACK, W. O.; WENSING C. J. G.. Tratado de anatomia veterinária. 3 ed. Rio de Janeiro: Elsevier, 2004, p. 496-501.

DYSON, S. An approach to the sport horse with potential thoracolumbar, lumbosacral or sacroiliac joint region pain. In: FOCUS MEETING OF THE AMERICAN ASSOCIATION OF EQUINE PRACTIONERS - LAMENESS AND IMAGING, 2007, Fort Collins. Proceedings... Colorado, USA, 2007. p. $142-148$.

EDDY, A. L.; VAN HOOGMOED, L. M.; SNYDER, J. R. The role of thermography in the manegement of equine lameness. Vet. J., v. 162, p. 172-181, 2001. 
FLEMING, P. Equine acupuncture In: SCHOEN, A. M.; WYNN, S. G. Complementary and alternative veterinary medicine: principles and practice. St. Louis: Mosby, 1998, p. 169184.

FONSECA, B. P. A. Termografia e ultra-sonografia no diagnóstico de lesões toracolombares em equinos atletas da raça Quarto de Milha. 2005. 71p. Dissertação (Mestrado) - Faculdade de Medicina Veterinária e Zootecnia, Universidade Estadual Paulista, Botucatu.

FONSECA, B. P. A.; ALVES, A.L.G; NICOLETTI, J.L.M.; THOMASSIAN, A.; HUSNI, C.A.; MIKAIL, $S$. Thermography and ultrasonography in back pain diagnosis of equine athletes. J. Equine Vet. Science, v. 26, n. 11, p. 507-516, 2006.

FONSECA, B. P. A. Protocolo de exame clínico e tratamento por ondas de choque da dor lombar em equinos da raça Quarto de Milha. 2008. 134p. Dissertação (Doutorado) Faculdade de Medicina Veterinária e Zootecnia, Universidade Estadual Paulista, Botucatu.

FRISBIE, D. D.; KAWCAK, C. E.; MCILWRAITH C. W. Evaluation of extracorporeal shock wave therapy for osteoarthritis. In: ANNUAL CONVENTION OF THE AMERICAN ASSOCIATION OF EQUINE PRACTIONERS, 50, 2004, Denver. Proccedings... Colorado, USA, 2004. p. 261-263.

GETTY, R. Osteologia equina. In: GETTY, R. Anatomia dos animais domésticos. v. 1, 5 ed. Rio de Janeiro: Guanabara Koogan, 1986, p. 233-323.

GILLIS, C. Spinal ligament pathology. Vet. Clin. North Am. Equine Pract., v. 15, n. 1, p. 97$101,1999$.

GIRODROUX, M.; DYSON, S.; MURRAY, R. Osteoarthritis of the thoracolumbar synovial intervertebral articulations: clinical and radiographic features in 77 horses with poor performance and back pain. Equine Vet. J. v. 41, n. 2, p. 130-138, 2009.

HARMAN J. C. Massage, stretching, homeopathy, and herbs. In: ROSS, M. W.; DYSON, S. J. Diagnosis and management of lameness in the hHorse. 1. ed. Philadelphia: Saunders, 2003, p. 815-817.

HAUSSLER, K. K. Anatomy of the thoracolumbar vertebral region. Vet. Clin. North Am. Equine Pract., v. 15, n. 1, p. 13-26, 1999a.

HAUSSLER, K. K. Osseous spinal pathology. Vet. Clin. North Am. Equine Pract., v. 15, n. 1, p. 103-112, 1999b.

HAUSSLER, K. K. Chiropractic evaluation and management. Vet. Clin. North Am. Equine Pract., v. 15, n. 1, p. 195-209, 1999c.

HAUSSLER, K. K. Equine chiropractic: general principles and clinical applications. In: ANNUAL CONVENTION OF THE AMERICAN ASSOCIATION OF EQUINE PRACTIONERS, 46, 2000, San Antonio. Proccedings... Texas, USA, 2000. p. 84-93.

HAUSSLER, K. K. Review of the examination and treatment of back and pelvic disorders. In: FOCUS MEETING OF THE AMERICAN ASSOCIATION OF EQUINE PRACTIONERS - LAMENESS AND IMAGING, Fort Collins, 2007. Proceedings... Colorado, USA, 2007. p. 158-182.

HENDRICKSON, D. A., Coluna toracolombar. In: STASHAK, T. S. Claudicação em equinos segundo Adams. 5 ed. São Paulo: Roca, 2006a, p. 990-998. 
HENDRICKSON, D. A., Problemas musculares. In: STASHAK, T. S. Claudicação em equinos segundo Adams. 5 ed. São Paulo: Roca, 2006b, p. 998-999.

LANDMAN, M. A. A. M.; BLAAUW, J. A.; VAN WEEREN, P. R.; HOFLAND, J. L. Field study of the prevalence of lameness in horses with back problems. Vet. Rec., v. 155, n. 6, p. 165-168, 2004.

MARKS, D. Medical management of the back pain. Vet. Clin. North Am. Equine Pract., v. 15, n. 1, p. 179-194, 1999.

MARTIN JUNIOR, B. B.; KLIDE, A. M. Physical examination of horses with back pain. Vet. Clin. North Am. Equine Pract., v. 15, n. 1, p. 61-70, 1999.

MARTIN JUNIOR, B. B.; KLIDE, A. M. Acupuntura para tratar dor lombar crônica de cavalos. In: SCHOEN, A. M. Acupuntura veterinária: da arte antiga à medicina moderna. 2 ed. São Paulo: Roca, 2006, p. 457-463.

MCCARROLL, G.D.; MCCLURE, S. Extracorporeal shock wave therapy for treatment of osteoarthritis of the tarsometatarsal and distal intertarsal joints of the horse. In: ANNUAL CONVENTION OF THE AMERICAN ASSOCIATION OF EQUINE PRACTIONERS, 46., 2000, San Antonio. Proceedings... Texas, 2000. p.200-202.

MCCLURE, S.R.; VAN SICKLE, D.; WHITE, R. Extracorporeal shock wave therapy: what is it? what does it do to equine bone? In: ANNUAL CONVENTION OF THE AMERICAN ASSOCIATION OF EQUINE PRACTIONERS, 46, 2000, San Antonio. Proccedings... Texas, USA, 2000. p. 197199.

MCCLURE, S. R.; SONEA, I. M.; YEAGER, M.; PAUWELS, F. E.; EVANS, R. B.; AMIN, V.; VAN SICKLE, D. Safety of shock wave therapy in performance horses. In: ANNUAL CONVENTION OF THE AMERICAN ASSOCIATION OF EQUINE PRACTIONERS, 49, 2003, New Orleans. Proceedings... Louisiana, USA, 2003. p. 62-65.

MCCLURE, S. Extracorporeal shock-wave therapy and radical pressure-wave therapy. In: ROBINSON N. E.; SPRAYBERRY K. A. Current therapy in equine medicine. 6 ed. Missouri: Saunders and Elsevie, 2009, p. 524-528.

MERRIAN, J. G. Acupuncture in the treatment of back and hindleg pain in sport horses. In: ANNUAL CONVENTION OF THE AMERICAN ASSOCIATION OF EQUINE PRACTIONERS, 43, 1997, Phoenix. Proceedings... Arizona, USA, 1997. p. 325-326.

MITCHELL, D. V. M., Approach to diagnosis and therapy of back pain. In: INTERNATIONAL CONGRESSO OF WORLD EQUINE VETERINARY ASSOCIATION, 2009, Guarujá. Proceedings... São Paulo, Brazil, 2009. p. 1-5.

NASCIMENTO, S. Mercado a galope. Globo Rural: cavalo vira bom negócio. São Paulo: Globo, ano 24, n. 287, p. 36-43, 2009.

PORTER, M. Equine rehabilitation therapy for joint disease. Vet. Clin. Equine. v. 21. p. 599$607,2005$.

PORTER, M. Rehabilitation therapy. In: ROBINSON N. E.; SPRAYBERRY K. A. Current therapy in equine medicine. 6 ed. Missouri: Saunders and Elsevie, 2009, p. 593-597.

REEF, V.B. Musculoeskeletal ultrasonography. In: REEF, V. B. Equine diagnostic ultrasound. Philadelphia: Saunders, 1998, p. 39-186. 
RIDGWAY, K. Acupuncture as a treatment modality for back problems. Vet. Clin. North Am. Equine Pract., v. 15, n. 1, p. 211-221, 1999.

RIDGWAY, K., HARMAN, J. Equine back rehabilitation. Vet. Clin. North Am. Equine Pract., v. 15, n. 1, p. 263-280, 1999.

SCHILS, S. J. Review of eletroterapy devices for use in veterinary medicine. In: ANNUAL CONVENTION OF THE AMERICAN ASSOCIATION OF EQUINE PRACTIONERS, 55, 2009, Las Vegas. Proceedings... Nevada, USA, 2009. p. 68-73.

SCHOEN, A. M. Equine acupuncture: incorporation into lameness diagnosis and treatment. In: ANNUAL CONVENTION OF THE AMERICAN ASSOCIATION OF EQUINE PRACTIONERS, 46, 2000, San Antonio. Proccedings... Texas, USA, 2000. p. 80-83.

SCHOEN, A. M. Acupuncture. In: ROSS, M. W., DYSON, S. J. Diagnosis and management of lameness in the horse. 1. ed. Philadelphia: Saunders, 2003, p. 793-803.

SISSON, S. Articulações dos equinos. In: GETTY, R. Anatomia dos animais domésticos. v. 1, 5 ed. Rio de Janeiro: Guanabara Koogan, 1986a, p. 324-349.

SISSON, S. Músculos do equino. In: GETTY, R. Anatomia dos animais domésticos. v. 1, 5 ed. Rio de Janeiro: Guanabara Koogan, 1986b, p.350-423.

STASHAK, T. S. Exame de claudicação. In: Claudicação em equinos segundo Adams. 5 ed. São Paulo: Roca, 2006, p. 91-152.

TOWNSEND, H.G.G., LEACH, D.H., FRETZ, P.B. Kinematics of the equine thoracolumbar spine. Equine Vet. J., v. 15, n. 2, p. 117-122, 1983.

TURNER, T. A. Use of thermography in lameness evaluation. In: ANNUAL CONVENTION OF THE AMERICAN ASSOCIATION OF EQUINE PRACTIONERS, 44, 1998, Baltilmore. Proceedings... Maryland, USA, 1998. p. 224-226.

TURNER, T. A.; PANSCH, J.; WILSON, J. H. Thermographic assesment of racing thoroughbreds. In: ANNUAL CONVENTION OF THE AMERICAN ASSOCIATION OF EQUINE PRACTIONERS, 47, 2001, San Diego. Proceedings... California, USA, 2001. p. 344-346.

TURNER, T. A. Back problems in horses. In: ANNUAL CONVENTION OF THE AMERICAN ASSOCIATION OF EQUINE PRACTIONERS, 49, 2003, New Orleans. Proceedings... Louisiana, USA, 2003. p. 71-74.

VALBeRG, S.J. Spinal muscle pathology. Vet. Clin. North Am. Equine Pract., v. 15, n. 1, p. 87-96, 1999.

VAN WESSUM, R. Evaluation of back pain by clinical examination. In: ROBINSON N. E.; SPRAYBERRY K. A. Current therapy in equine medicine. 6 ed. Missouri: Saunders and Elsevie, 2009, p. 469-473.

VON SCHWEINITZ, D.G. Thermografic diagnostics in equine back pain. Vet. Clin. North Am. Equine Pract., v. 15, n. 1, p. 161-177, 1999.

WEAVER, M. P.; JEFFCOTT, L. B.; NOWAK, M. Radiology and scintigraphy. Vet. Clin. North Am. Equine Pract., v. 15, n. 1, p. 113-129, 1999. 